University of Windsor

Scholarship at UWindsor

2005

\title{
Minimizing invasion risk by reducing propagule pressure: a model for ballast-water exchange
}

\author{
Marjorie J. Wonham \\ University of Windsor \\ Mark A. Lewis \\ University of Windsor \\ Hugh J. Maclsaac \\ University of Windsor
}

Follow this and additional works at: https://scholar.uwindsor.ca/biologypub

Part of the Biology Commons

\section{Recommended Citation}

Wonham, Marjorie J.; Lewis, Mark A.; and Maclsaac, Hugh J., "Minimizing invasion risk by reducing propagule pressure: a model for ballast-water exchange" (2005). Frontiers in Ecology and the Environment, 3, 9, 473-478.

https://scholar.uwindsor.ca/biologypub/1099

This Article is brought to you for free and open access by the Department of Biological Sciences at Scholarship at UWindsor. It has been accepted for inclusion in Biological Sciences Publications by an authorized administrator of Scholarship at UWindsor. For more information, please contact scholarship@uwindsor.ca. 


\title{
Minimizing invasion risk by reducing propagule pressure: a model for ballast- water exchange
}

\author{
Marjorie J Wonham ${ }^{1,2 *}$, Mark A Lewis ${ }^{1}$, and Hugh J MacIsaac ${ }^{2}$
}

\begin{abstract}
Biological invasions are a major and increasing agent of global biodiversity change. Theory and practice indicate that invasion risk can be diminished by reducing propagule pressure, or the quantity, quality, and frequency of introduced individuals. For aquatic invasions, the primary global invasion pathway is ballast-water transport, and the primary risk reduction strategy is currently open-ocean exchange. Exchange was developed with shipping between freshwater ports in mind, but the majority of shipping connects brackish and marine ports. A worldwide convention, adopted in 2004 by the International Maritime Organization, now mandates ballast-water exchange (or equivalent management) for its 164 member states. Will exchange be as effective in reducing invasion risk for euryhaline species (those capable of tolerating a wide range of salinity levels) in saltwater ports? Here we develop a simple mathematical framework for optimizing ballast-water exchange in terms of exchange level, timing, and species salinity tolerance. Our model shows that when species survival is worse in the post-exchange than in the pre-exchange water, exchange is always effective. However, when survival is equal or better following exchange, a critical level and timing are required for effective exchange. We illustrate the model's applications with a variety of introduced marine and estuarine organisms.
\end{abstract}

Front Ecol Environ 2005; 3(9): 473-478

B iological invasions, a major and increasing agent of global biodiversity change, are often the result of inadvertent releases from trade and travel pathways (Levine et al. 2003; Ruiz and Carlton 2003; Drake and Lodge 2004). Empirical and theoretical evidence indicate that invasion risk can be decreased by reducing propagule pressure, specifically, the quantity, quality, and frequency of introduced individuals (Grevstad 1999; Rouget and Richardson 2003; Drake and Lodge 2004; Verling et al. 2005). In marine and estuarine systems, the dominant invasion pathway worldwide is the ballast water of commercial ships (Carlton and Geller 1993; Carlton 1998; Ruiz and Carlton 2003; Drake and Lodge 2004; Holeck et al. 2004). Current estimates suggest that a global fleet of approximately 35000 commercial vessels transports an annual volume of about $3.5 \times 10^{9}$ metric tons of ballast water, containing some 7000-10000 species - mostly marine - at any one time (Carlton 1999; Endresen et al. 2004; Figure 1)

This invasion pathway is currently managed primarily by open-ocean ballast-water exchange (IMO 2004; Minton et al. 2005). Under this practice, a ship's ballast tanks are loaded as usual at the start of a voyage, emptied

${ }^{1}$ Centre for Mathematical Biology, Department of Biological Sciences and Department of Mathematical and Statistical Sciences, University of Alberta, CAB 632, Edmonton, AB T6G 2G1, Canada*(mwonham@ualberta.ca); ${ }^{2}$ Great Lakes Institute for Environmental Research, University of Windsor, Windsor, ON N9B 3P4, Canada and refilled in mid-ocean, and subsequently emptied in or near the destination port (Figure 2). Exchange is based on three assumptions: (1) that most initial organisms are flushed out; (2) that remaining organisms survive poorly, if at all, in the newly ballasted ocean water; and (3) that oceanic organisms released in the destination port pose a minimal invasion risk. We focus here on the interaction between the first and second assumptions in determining exchange effectiveness.

Ballast-water exchange was originally developed in the context of ships sailing from fresh-through saltwater back to freshwater, so that any freshwater organisms remaining after exchange would be expected to die in the newly loaded oceanic water. Exchange has since been recommended or required by a number of coastal ports and nations, and a recently adopted International Maritime Organization convention now requires vessels arriving in all 164 member states to conduct open-ocean exchange or equivalent management (IMO 2004; Minton et al. 2005). However, it is not clear if exchange would be as effective for saltwater organisms, where post-exchange survival in oceanic water could be equal to or greater than that in the initial water.

Here we develop a simple theoretical framework for evaluating and maximizing the effectiveness of ballastwater exchange. Using this framework, we show when exchange is predicted to reduce propagule pressure, and when it can, counterintuitively, increase propagule pressure relative to a nonexchanged tank. We then apply the model to evaluate exchange effectiveness for a series of 


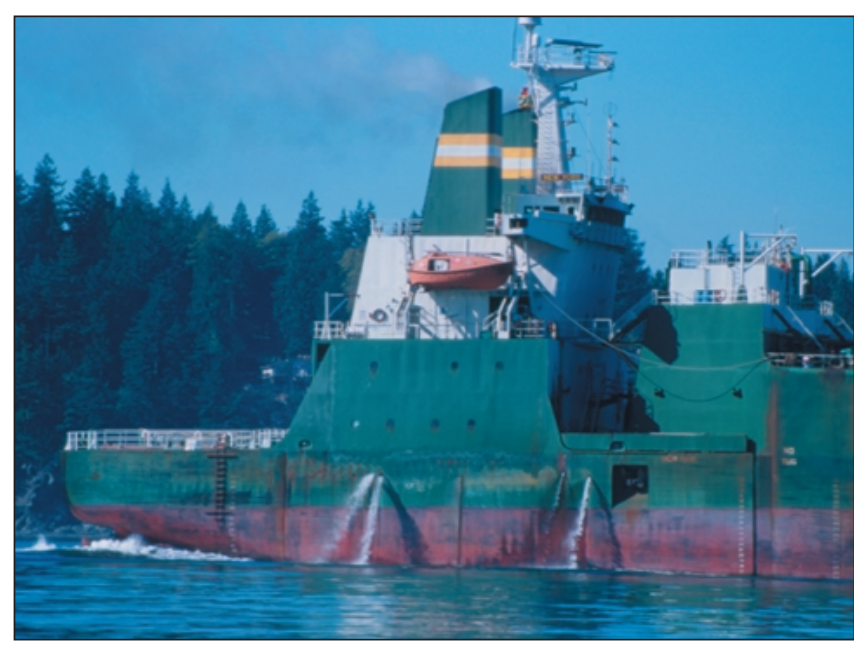

Figure 1. Vessel deballasting in coastal waters.

introduced marine and estuarine species. Although this framework is developed with reference to exchange, it could readily be applied to other ballast treatment methods (eg Waite et al. 2003; Minton et al. 2005) during or at either end of a voyage.

\section{Ballast-exchange model}

\section{Model structure}

Our goal is to model organism survival in ballast-water tanks with and without exchange. Based on empirical results (Gollasch et al. 2000; Wonham et al. 2001; Drake et al. 2002; Taylor et al. 2002; Murphy et al. 2004), we model the abundance of a single species in a single ship as declining exponentially both before and after exchange. We use the following equation modified from equation 7 of MacIsaac et al. (2002):

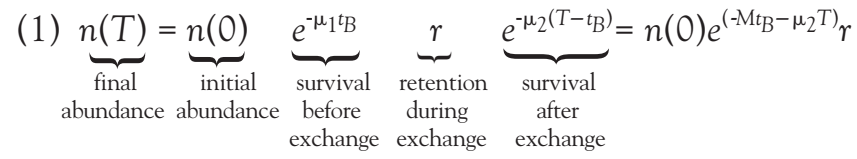

Here, $n(T)$ is the final organism abundance at the end of a ballast voyage of length $T$ days and $n(0)$ is the initial abundance. Exchange occurs on day $t_{\mathrm{B}}<T$, and $r$ is the proportion of organisms retained during exchange, giving exchange efficiency as $1-r$. The difference in per capita daily mortality rates in initial $\left(\mu_{1}\right)$ and exchanged $\left(\mu_{2}\right)$ water is $M=\mu_{1}-\mu_{2}$. Since we are considering organism abundance within the ship only, we leave off the original ballast discharge parameter $r_{1}$. In the absence of exchange, equation (1) simplifies to:

$$
\underbrace{n(T)}_{\begin{array}{c}
\text { final } \\
\text { abundance }
\end{array}}=\underbrace{n(0)}_{\begin{array}{c}
\text { initial } \\
\text { abundance }
\end{array}} \underbrace{e^{-\mu_{1} T}}_{\begin{array}{c}
\text { survival } \\
\text { over } \\
\text { voyage }
\end{array}}
$$

as in MacIsaac et al. (2002) equation 8.

For simplicity, we consider the abundance of a single ballasted species, and do not consider any new organisms produced during the voyage, loaded during open-ocean ballast exchange, or hatched from ballast sediments (eg Gollasch et al. 2000; Wonham et al. 2001; Taylor et al. 2002; Murphy et al. 2004; Wonham et al. in press). Species mortality rates $\mu_{1}$ and $\mu_{2}$ are not associated with freshwater and saltwater per se, as in MacIsaac et al. (2002), but simply with pre-exchange and post-exchange ballast water. We assume that both mortality rates are constant, which is consistent with empirical data for many but not all taxa (Gollasch et al. 2000; Wonham et al. 2001; Drake et al. 2002; Taylor et al. 2002).

\section{Model analysis}

We define exchange as effective if it reduces the final organism abundance $n(T)$ relative to that in a nonexchanged tank. To obtain the conditions for effective exchange, we set equation (1) < equation (2), and find that exchange is effective if, and only if:

$$
\text { (3) } r<e^{M\left(t_{B}-T\right)} \text {. }
$$

When the mortality rate is greater after than before exchange, $M<0$ and inequality (3) always holds. For $M \geq 0$, inequality (3) means that effective exchange occurs only below a threshold value of exchange retention $r<r^{*}=e^{\mathrm{M}\left(t_{B}-T\right)}$. Assuming $r<1$, this expression can be rearranged to give the threshold exchange day $t_{B}>t_{B}^{*}=\ln (r) / M+T$, or the threshold difference in mortality rates, $M<M^{*}=\ln (r) /\left(t_{B}-T\right)$ required for effective exchange. In the last expression, a higher value of $M^{*}$ generated by more efficient or later exchange (ie as $r \rightarrow 0$ or $t_{B} \rightarrow T$ ) indicates that exchange will be effective over a wider range of $M \geq 0$. As $M^{*}$ decreases with lower or earlier exchange (ie as $r \rightarrow 1$ or $t_{B} \rightarrow 0$ ), exchange will be effective only for species with lower values of $M$.

This model illustrates that for species with $M<0$, exchange is always effective (Figure 3a). We would generally expect this to be the case for freshwater organisms exposed to seawater during open-ocean exchange. For estuarine and marine organisms, we might still expect $M<0$ if the ocean water were less hospitable than the initial water in terms of salinity or other factors. On the other hand, if the ocean water were equally or more hospitable, we could find $M \geq 0$. In this case, exchange effectiveness would depend on the exchange retention and timing (Figure 3a).

For a given $M$ value, exchange operations can be optimized to minimize the final organism abundance $n(T)$. This is illustrated for a fixed value of $r=0.1$, with examples of earlier $\left(t_{B}=3\right)$ and later $\left(t_{B}=7\right)$ exchange (Figure 3b). When $M<0$, earlier exchange leads to the lowest value of $n(T)$. When $0<M<M^{*}$, later exchange leads to the lowest $n(T)$. In the region $M>M^{*}, n(T)$ is minimized by not exchanging ballast water (Figure $3 \mathrm{~b}$ ).

The above calculations would ensure effective 
exchange when that is defined simply as a reduction in $n(T)$ relative to a non-exchanged tank. In a more realistic approach, we consider a target reduction in organism abundance to be $x \%$ of a nonexchanged tank. We then obtain, for $M \geq 0$, the more general threshold expressions for effective exchange, $r<r^{*}=$ $x e^{\mathrm{M}\left(t_{B}-T\right)}, t_{B}>t^{*}{ }_{B}=\ln (r / x) / M+T$, and $\mathrm{M}<\mathrm{M}^{*}=\ln (r / x) /\left(t_{B}-T\right)$. In other words, the lower the value of $x$, the

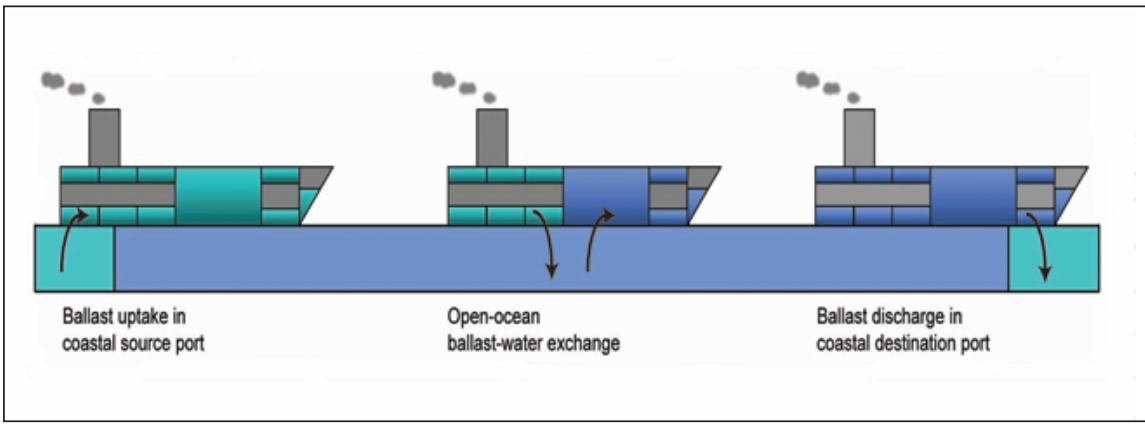

Figure 2. Illustration of the ballast-water exchange process.

lower $r$ must be, the later $t_{B}$ must be, or the lower M must be for effective exchange. To illustrate the model's application to particular species, we use the special case shown in inequality (3) where $x=1$.

\section{Application to estuarine and marine species}

To illustrate the application of this model, we assumed as a first approximation that the only difference between the initial and oceanic ballast water was salinity. We conducted a literature search to obtain published data on proportional survival $p$ over a given number of days $d$ at lower and higher salinity levels $i$ for known introduced estuarine and marine species. We then estimated each species' daily mortality rate $\mu_{i}$ as $e^{-\mu_{i} d}=p$ (following MacIsaac et al. 2002). We assumed that the lower salinity mortality rate applied in the pre-exchange coastal water, and the higher salinity rate in the post-exchange oceanic water. From these mortality rates, we determined the threshold retention $r^{*}$ and timing $t_{B}^{*}$ of exchange. When multiple data were available in the original sources, we preferentially selected those for planktonic larval and

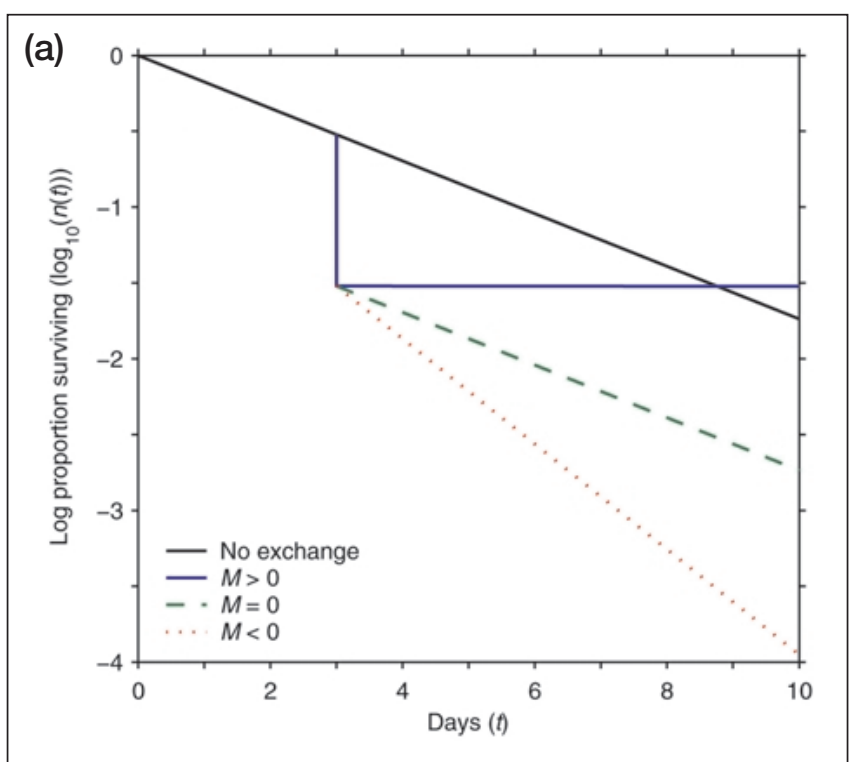

juvenile stages at temperatures $10-20^{\circ} \mathrm{C}$, with salinities as close as possible to the lower range $20-29 \%$ and the higher range 30-35\%. Although the laboratory studies we used were not designed explicitly to test ballast exchange, they provide preliminary data for examining the biological constraints on effective exchange.

Of the resulting mortality rate estimates, almost all were in the range $0 \leq \mu_{i}<0.3$, which is generally consistent with the empirically observed range for invertebrate zooplankton in ballast tanks (eg 0.02-0.22; Wonham et al. 2001; Table 1). In approximately half the cases, $M \leq 0$. In these cases, any exchange level $r<1$ is predicted to reduce $n(T)$ relative to a non-exchanged tank (Table 1 ). Of these cases, when $M=0$, exchange timing does not affect $n(T)$; when $M<0$, exchange on any day is effective and the earlier the exchange, the greater its effectiveness.

For the remaining half of the cases, $\mathrm{M}>0$. Here, exchange is effective only for certain values of $r$ and $t_{B}$. For example, if we fix $t_{\mathrm{B}}=5$ and $T=10$, the threshold retention value $r^{*}$ ranges from $0.12-0.99$, corresponding to a minimum exchange efficiency of $1-r^{*}=0.01-0.88$ (Table 1). If $r<r^{*}$, exchange would lead to a higher $n(T)$

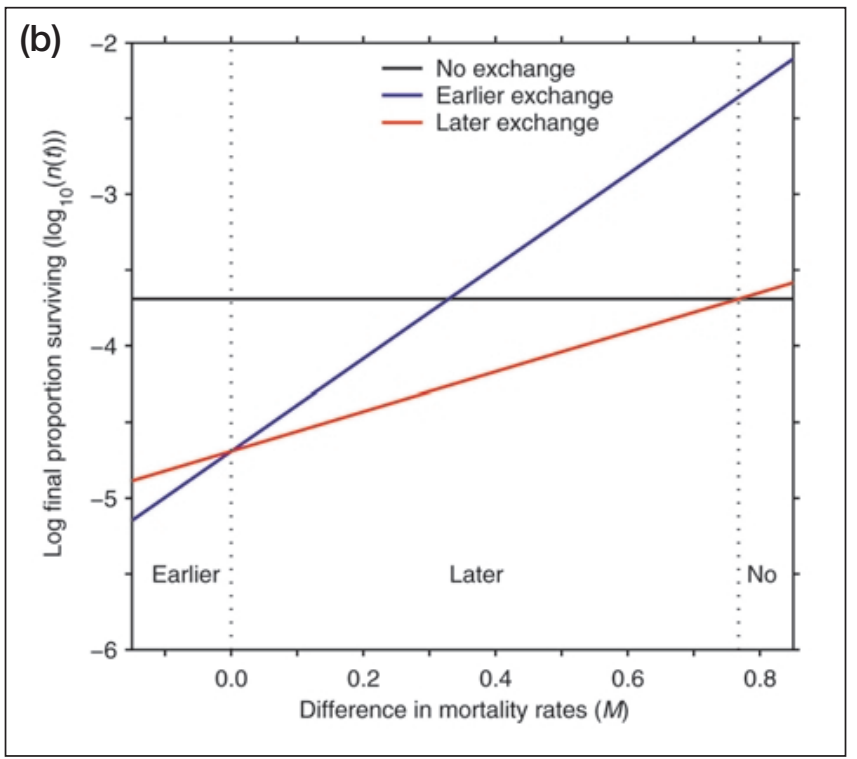

Figure 3. Ballast-exchange model predictions. In (a), the proportion of organisms surviving in a ballast tank depends on the difference in mortality rates $\mathrm{M}=\mu_{1}-\mu_{2}$, (parameter values $\mu_{1}=0.4 ; \mu_{2}=0.001$ [blue solid], 0.04 [green dashed], 0.8 [red dotted]; $\left.\mathrm{r}=0.1 ; \mathrm{t}_{\mathrm{B}}=3 ; \mathrm{T}=10\right)$. In $(b)$, vertical dotted lines separate regions of $\mathrm{M}$ for which no, later, and earlier exchange minimize $\mathrm{n}(\mathrm{T})$ (parameter values $\mu_{1}=0.85, \mu_{2}=[0,1] ; \mathrm{r}=0.1 ; \mathrm{t}_{\mathrm{B}}=3$ [earlier], and 7 [later]; $\mathrm{T}=10$ ). 


\begin{tabular}{|c|c|c|c|c|c|c|}
\hline Species $^{a}$ & Stage & $\mu_{l}$ & $\mu_{2}$ & M & $r^{*}$ & $t_{B}^{*}$ \\
\hline \multirow[t]{2}{*}{ Japanese oyster ${ }^{\prime}$} & early larvae & 0.000 & 0.000 & 0.000 & 1.00 & - \\
\hline & late larvae & 0.000 & 0.063 & -0.063 & 1.00 & + \\
\hline Eastern oyster ${ }^{2}$ & embryos & 0.015 & 0.200 & -0.185 & 1.00 & + \\
\hline Atlantic pearl oyster ${ }^{3}$ & larvae & 0.602 & 0.178 & 0.424 & 0.12 & 2.3 \\
\hline Mediterranean mussel $^{4}$ & larvae & 0.090 & 0.088 & 0.002 & 0.99 & 3.9 \\
\hline Japanese littleneck clam ${ }^{5}$ & larvae & 0.000 & 0.000 & 0.000 & 1.00 & - \\
\hline \multirow[t]{2}{*}{ Veined rapa whelk ${ }^{6}$} & early larvae & 0.093 & 0.255 & -0.162 & 1.00 & + \\
\hline & late larvae & 0.005 & 0.020 & -0.015 & 1.00 & + \\
\hline Signal crayfish ${ }^{7}$ & juveniles & 0.004 & 0.111 & -0.108 & 1.00 & + \\
\hline \multirow[t]{4}{*}{ Eurasian green $\mathrm{crab}^{8}$} & zoea I & 0.182 & 0.032 & 0.150 & 0.47 & 2.4 \\
\hline & zoea 2 & 0.099 & 0.068 & 0.031 & 0.86 & 2.6 \\
\hline & zoea 3 & 0.090 & 0.046 & 0.045 & 0.80 & 2.5 \\
\hline & zoea 4 & 0.095 & 0.037 & 0.058 & 0.75 & 2.5 \\
\hline \multirow[t]{6}{*}{ Chinese mitten $\mathrm{crab}^{9}$} & zoea I & 0.025 & 0.054 & -0.030 & 1.00 & + \\
\hline & zoea 2 & 0.008 & 0.013 & -0.005 & 1.00 & + \\
\hline & zoea 3 & 0.000 & 0.000 & 0.000 & 1.00 & - \\
\hline & zoea 4 & 0.015 & 0.000 & 0.015 & 0.93 & 2.8 \\
\hline & zoea 5 & 0.009 & 0.005 & 0.004 & 0.98 & 3.5 \\
\hline & megalopa & 0.018 & 0.038 & -0.020 & 1.00 & + \\
\hline Gammarid amphipod ${ }^{10}$ & adults & 0.098 & 0.768 & -0.669 & 1.00 & + \\
\hline Calanoid copepod" & juveniles & 0.048 & 0.005 & 0.044 & 0.80 & 2.5 \\
\hline Northern Pacific seastar ${ }^{12}$ & larvae & 0.227 & 0.231 & -0.004 & 1.00 & + \\
\hline
\end{tabular}

than in a nonexchanged tank. For comparison, empirical estimates of exchange efficiency range from $<0.5$ to $>$ 0.99 (eg Taylor et al. 2002), which corresponds to $r$-values from under 0.01 to over 0.5.

Alternatively, if we fix $r=0.1$ and $T=10$, we obtain the threshold value $t_{B}^{*}$, which ranges from 2.4-3.9. For $M$ $>0$, exchange would be effective only if conducted on day $t_{B}>t_{B}^{*}$; prior to $t_{B}^{*}$, it would be counterproductive (Table 1). These critical exchange rates would be more readily achieved on some voyages than others. For example, the average voyage distances of vessels arriving in US ports are $1100 \mathrm{~km}$ and $8275 \mathrm{~km}$ (Drake and Lodge 2004), which at an average sailing speed of 15 knots corresponds to voyage lengths of approximately 1.6 and 12.4 days. These estimates are consistent with observed intracoastal and interoceanic voyage lengths reported for selected US ports (Smith et al. 1999; Verling et al. 2005). Thus, values of $t_{\mathrm{B}}$ greater than 2 to 4 days would be more feasible for longer transoceanic than for shorter intracoastal voyages.

More generally, we can visualize the range of effective combinations of ballast exchange retention and timing by plotting contour values of $r^{*}$ as a function of $t_{B}$ and $M$ (Figure 4a). For a species with a given $M$ value, multiple combinations of $r$ and $t_{\mathrm{B}}$ can be determined to ensure effective exchange. For example, exchange would be effective for the pearl oyster (Pinctada imbricata; $M=$ 0.42 ) with a combination of $r<0.9$ and $t_{B}>4.5$, or $r<0.7$ and $t_{B}>7$ (Figure 2a). For the Eurasian green crab (Carcinus maenas), which has a lower $M$ value (first zoeal stage $M=0.15$ ), effective exchange on the same days would require more efficient exchange with a lower $r$ value (Figure 4a).

Some species have different $M$ values at different life stages (Table 1), in which case the same exchange strategy may not be optimal for all stages (Figure 4b). In the Chinese mitten crab (Eriocheir sinensis), for example, the first and second zoeal stages have $M<0$ so earlier exchange would minimize $n(T)$. In the third stage, where $M=0$, exchange timing would not affect $n(T)$. In the fourth and fifth stages, $M>0$, so later exchange would minimize $n(T)$ (Figure 4b).

\section{Summary}

Population and genetic theory predict that the chances of successful biological invasion increase with the number, frequency, and quality of individuals released. Ballastwater exchange represents a global-scale implementation 

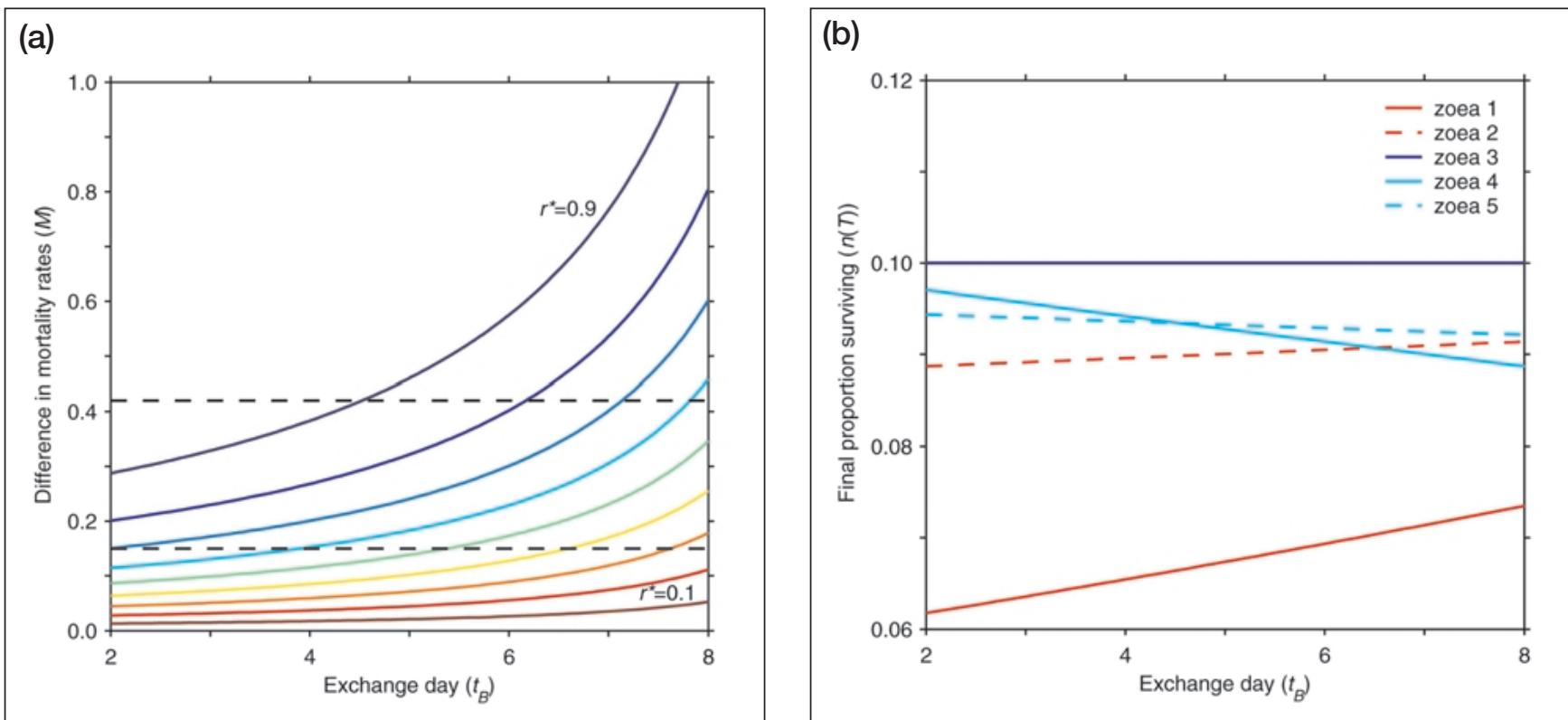

Figure 4. Using the ballast-exchange model to optimize exchange strategy. In (a), contours of the critical value $\mathrm{r}^{*}$ from 0.1 to 0.9 are plotted as a function of $\mathrm{M}$ and $\mathrm{t}_{\mathrm{B}}$. For a given species' $\mathrm{M}$ value, shown as lower horizontal dashed line for Eurasian green crab (Carcinus maenas) and upper for Atlantic pearl oyster (Pinctada imbricata), different effective combinations of $\mathrm{r}$ and $\mathrm{t}_{\mathrm{B}}$ can be selected to ensure effective exchange. In (b), five larval stages of the Chinese mitten crab (Eriocheir sinensis) have different $\mathrm{M}$ values and therefore different optimal exchange strategies (shown for $\mathrm{r}=0.1$ and $\mathrm{T}=10$ ).

of this theory designed to reduce propagule pressure and invasion risk in aquatic and marine systems. Although exchange is increasingly being adopted by port states worldwide (IMO 2004) it has been tested empirically in only a few instances (eg Taylor et al. 2002).

Here, we have provided a simple model to investigate when and how much exchange reduces propagule pressure,

\begin{tabular}{|c|c|}
\hline \multicolumn{2}{|c|}{ Panel 1. Model parameters } \\
\hline Symbol & Meaning \\
\hline$n(0)$ & initial organism abundance in ballast tank \\
\hline$n(T)$ & final organism abundance in ballast tank \\
\hline$\mu_{1}$ & $\begin{array}{l}\text { daily per capita mortality rate before } \\
\text { exchange, } 0 \leq \mu_{1} \leq \mathrm{I}\end{array}$ \\
\hline$\mu_{2}$ & $\begin{array}{l}\text { daily per capita mortality rate after } \\
\text { exchange, } 0 \leq \mu_{2} \leq 1\end{array}$ \\
\hline$T$ & voyage duration in days \\
\hline M & difference in mortality rates, $\mu_{1}-\mu_{2}$ \\
\hline$M^{*}$ & $\begin{array}{l}\text { critical difference: only when } M<M^{*} \text { will } \\
\text { exchange reduce } n(T) \text { relative to a } \\
\text { nonexchanged tank }\end{array}$ \\
\hline$t_{B}$ & day of ballast exchange, $t_{B}<T$ \\
\hline$t_{B}^{*}$ & $\begin{array}{l}\text { critical exchange day: only when } t_{B}>t_{B}^{*} \\
\text { will exchange reduce } n(T) \text { relative to } \\
\text { a nonexchanged tank }\end{array}$ \\
\hline$r$ & $\begin{array}{l}\text { proportion of organisms remaining } \\
\text { following exchange, } 0 \leq r \leq 1\end{array}$ \\
\hline$r^{*}$ & $\begin{array}{l}\text { critical proportion: only when } r<r^{*} \text { will } \\
\text { exchange reduce } n(T) \text { relative to a } \\
\text { nonexchanged tank }\end{array}$ \\
\hline $\mathrm{I}-\mathrm{r}$ & exchange efficiency \\
\hline
\end{tabular}

and how this reduction can be optimized. Depending on the species, maximum invasion risk reduction may be achieved by early exchange, late exchange, or no exchange at all. Although there exists a parameter space in which exchange is counterproductive, leading to increased propagule pressure relative to a nonexchanged tank, we find that exchange is generally predicted to be effective for the introduced estuarine and marine species we examined. In many cases, though, there is a minimum exchange level or timing required for effectiveness. Of course, these calculated critical values would apply only to a vessel far enough from the coast to conduct open-ocean exchange, since exchanging too close to the departure or arrival port would defeat the purpose (Taylor et al. 2002; IMO 2004).

To introduce this modeling framework, we made several simplifying assumptions that could be investigated with further extensions to the model. Our model incorporates the first two underlying assumptions of ballast exchange, organism flushing during and mortality following exchange, but the third assumption of minimal survival of oceanic organisms in coastal waters remains to be assessed. Although we developed this model for a single species or life stage, a ballast assemblage typically consists of multiple species and life stages, with a resulting wide range of optimal exchange strategies that need to be considered together. Additional aspects of the ballast community, including organisms hatching and reproducing during the voyage, could also be incorporated (eg Wonham et al. in press). We assumed that exchange affected only ballast-water salinity, although it may also affect oxygen, pollutant, and nutrient levels, as well as species composition, all of which could influence mortality rates. We also assumed that mortality rates 
before and after exchange were constant, although empirical evidence shows that they can vary (Gollasch et al. 2000; Wonham et al. 2001; Drake et al. 2002; Taylor et al. 2002). A more complex model could incorporate a range of mortality functions dependent on multiple environmental variables. Finally, the observed variation in the ballast assemblage and environment indicates the importance of considering alternate management strategies to complement ballast-water exchange in reducing invasion risk (eg Carlton 1998; Taylor et al. 2002; Minton et al. 2005). Modifications of our model could be readily used for similar analyses of other emerging ballast-treatment methods.

\section{Acknowledgments}

This work was supported by NSERC and The Killam Trusts (MJW), by NSERC Discovery grants, an NSERC CRO grant, and NSF grant DEB 02-13698 (MAL, HJM), by a Canada Research Chair (MAL), and by a DFO Research Chair and the Great Lakes Protection Fund (HJM). We are grateful to A Potapov for Russian literature translations.

\section{References}

Carlton JT and Geller JB. 1993. Ecological roulette: the global transport of nonindigenous marine organisms. Science 261: $78-82$.

Carlton JT (Ed). 1998. Ballast water: ecological and fisheries implications. Copenhagen, Denmark: International Council for the Exploration of the Seas (ICES). Cooperative Research Report.

Drake JM and Lodge DM. 2004. Global hot spots of biological invasions: evaluating options for ballast-water management. P Roy Soc Lond B 271: $575-80$.

Drake LA, Ruiz GM, Galil BS, et al. 2002. Microbial ecology of ballast water during a transoceanic voyage and the effects of openocean exchange. Mar Ecol Prog Ser 233: 13-20.

Endresen $\varnothing$, Behrens HL, Brynestad S, et al. 2004. Challenges in global ballast water management. Mar Poll Bull 48: 615-23.

Gollasch S, Dammer M, Lenz J, and Andres HG. 2000. Survival of tropical ballast water organisms during a cruise from the Indian Ocean to the North Sea. J Plankton Res 22: 923-37.

Grevstad FS. 1999. Experimental invasions using biological control introductions: the influence of release size on the chance of population establishment. Biol Invasions 1: 313-23.

Holeck KT, Mills EL, MacIsaac HJ, et al. 2004. Bridging troubled waters: biological invasions, transoceanic shipping, and the Laurentian Great Lakes. BioScience 54: 919-29.

IMO (International Maritime Organization). 2004. International convention for the control and management of ships ballast water and sediments. Adopted 13 February 2004.

Levine JM and D'Antonio CM. 2003. Forecasting biological invasions with increasing international trade. Conserv Biol 17: 322-26.

MacIsaac HJ, Robbins TC, and Lewis MA. 2002. Modeling ships' ballast water as invasion threats to the Great Lakes. Can J Fish Aquat Sci 59: 1245-56.

Minton MS, Verling E, Miller AW, and Ruiz GM. 2005. Reducing propagule supply and coastal invasions via ships: effects of emerging strategies. Front Ecol Env 3: 304-08.

Murphy K, Boehme J, Coble P, et al. 2004. Verification of mid-ocean ballast water exchange using naturally occurring coastal tracers. Mar Poll Bull 48: 711-30.

Rigby G and Hallegraeff G. 1994. The transfer and control of harm- ful marine organisms in shipping ballast water: behavior of marine plankton and ballast water exchange trials on the MV "Iron Whyalla". J Mar Environ Eng 1: 91-110.

Rouget M and Richardson DM. 2003. Inferring process from pattern in plant invasions: a semi-mechanistic model incorporating propagule pressure and environmental factors. Am Nat 162: 713-24.

Ruiz GM and Carlton JT (Eds). 2003. Invasive species: vectors and management strategies. Washington, DC: Island Press.

Taylor A, Rigby G, Gollasch S, et al. 2002. Preventive treatment and control techniques for ballast water. In: Leppäkoski E, Gollasch S, and Olenin S (Eds). Invasive aquatic species of Europe: distribution, impacts and management. Dordrecht, The Netherlands: Kluwer Academic Publishers.

Verling E, Ruiz GM, Smith LD, et al. 2005. Supply-side invasion ecology: characterizing propagule pressure in coastal ecosystems. Proc R Soc Lond B 272: 1249-56.

Waite TD, Kazumi J, Lane PVZ, et al. 2003. Removal of natural populations of marine plankton by a large-scale ballast water treatment system. Mar Ecol Prog Ser 258: 51-63.

Wonham MJ, Walton WC, Ruiz GM, et al. 2001. Going to the source: role of the invasion pathway in determining potential invaders. Mar Ecol Prog Ser 215: 1-12.

Wonham MJ, Bailey SA, MacIsaac HJ, and Lewis MA. Modelling the invasion risk of diapausing organisms transported in ballast sediments. Can J Fish Aquat Sci. In press.

\section{Parameter estimation sources}

Anger K. 1991. Effects of temperature and salinity on the larval development of the Chinese mitten crab Eriocheir sinensis (Decapoda: Grapsidae). Mar Ecology Prog Ser 72: 103-10.

Anger K, Spivak E, and Luppi T. 1998. Effects of reduced salinities on development and bioenergetics of early larval shore crab, Carcinus maenas. J Exp Mar Biol Ecol 220: 287-304.

Bruijs MCM, Kelleher B, van der Velde G, and bij de Vaate A. 2001. Oxygen consumption, temperature and salinity tolerance of the invasive amphipod Dikerogammarus villosus: indicators of further dispersal via ballast water transport. Archiv Hydrobiol 152: 633-46.

Davis HC. 1958. Survival and growth of clam and oyster larvae at different salinities. Biol Bull 114: 296-307.

Holdich DM, Harlioğlu MM, and Firkins I. 1997. Salinity adaptations of crayfish in British waters with particular reference to Austropotamobius pallipes, Astacus leptodactylus and Pacifastacus leniusculus. Est Coast Shelf Sci 44: 147-54.

Lee CE and Petersen CH. 2002. Genotype-by-environment interaction for salinity tolerance in the freshwater invading copepod Eurytemora affinis. Physiol Biochem Zool 75: 335-44.

Mann R and Harding JM. 2003. Salinity tolerance of larval Rapana venosa: implications for dispersal and establishment of an invading predatory gastropod on the North American Atlantic coast. Biol Bull 204: 96-103.

Matson SE. 2000. Hybridization of the mussels Mytilus trossulus and M galloprovincialis: larval growth, survival and early development (PhD dissertation). Seattle, WA: University of Washington.

Namaguchi K. 1998. Preliminary experiments on the influence of water temperature, salinity and air exposure on the mortality of Manila clam larvae. Aquacult Internat 6: 77-81.

O'Connor WA and Lawler NF. 2004. Salinity and temperature tolerance of embryos and juveniles of the pearl oyster, Pinctada imbricata Röding. Aquaculture 229: 492-506.

Sutton CA and Bruce BD. 1996. Temperature and salinity tolerances of the larvae of the northern Pacific seastar Asterias amurensis. CRIMP (Centre for Research on Introduced Marine Pests). Hobart, Australia: CSIRO Marine Research. Technical Report 6.

Yaroslavtseva LM and Sergeeva EP. 2001. Salinity adaptations of the gastropods Littorina mandschurica and $L$ squalida from marine and estuarine water habitats. Biologiya Morya 27: 286-91. 